\title{
Treatment of Peri-Implantitis:
}

\section{A New Approach}

JM. Cervera Maillo, H. Morales Melendez, D. Morales Schwarz

\section{Abstract}

Aim: We propose a new approach in the treatment of mucositis and peri-implantitis by adding an epithelial tissue graft.The aim of this study is to prove if an increase of the keratinized mucosa improves the clinical and radiographic parameters of the periimplant diseases evaluating it at the 6 and 12 months after the treatment.

- Material and methods: 32 patients with clinicall and radiographicall signs of peri-implantitis and less than $2 \mathrm{~mm}$ of keratinized attached mucosa were threated with palatal graft fixed with self tapping microscrewsfullfiled the inclusion criteria. Patients were reviewed at 10 days, one month, 6 month and one year. Persistence of clinical signs of peri-implantitis. recession and radiographicall bone loss were assesed.

- Results: At 10 days all free palatal grafts healed uneventful. At six month 30 implant sites showed clinical resolution of peri-implantitis. No further bone loss could be observed. At one year 29 implants showed resolution of perimiplant conditions. No further bone loss occured. At one year $91 \%$ of the implants showed a mean $2 \mathrm{~mm}$ creeping attachment over the exposed implant neck.

- Conclusions: Free gingival graft with self tapping micro-screws presents many advantages over the conventional suturing method.The described method, is helpful in treating mucositis and periimplantitis.

\section{Background and Aim}

There is no clear scientific evidence of which is the best treatment for peri-implantitis. We propose a new approach in the treatment of mucositis and peri-implantitis by adding an epithelial tissue graft. The aim is to give biological tissue stability that remain in time favoring balance and resetting the biological width complex.

We document the phenomena "creeping attachment" around implants in which the gingiva creeps over the exposed implant neck, producing a mean tissue gain of more than $2 \mathrm{~mm}$.

The aim of this study is to prove if an increase of the keratinized mucosa improves the clinical and radiographic parameters of the peri-implant diseases evaluating it at the 6 and 12 months after the treatment.

\section{Methods and Materials}

32 patients with clinical and radiographical signs of peri-implantitis and less than $2 \mathrm{~mm}$ of keratinized attached mucosa fullfiled the inclusion criteria. The procedure is performed by doing a vestibuloplasty, fixing all the mobile tissue apically, using soft tissue microscrews and grafting the exposed area with a palatal free gingival graft of keratinized

mucosa fixed with self tapping microscrews. Patients were reviewed at

10 days, one month, 6 month and one year. Persistence of clinical

signs of peri-implantitis. recession and radiographicall bone loss were assesed.

APICAL REPOSITIONING AND

STABILIZATION OF MUSCULAR FIBERS.
SELF TAPPING SCREWS

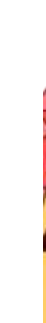
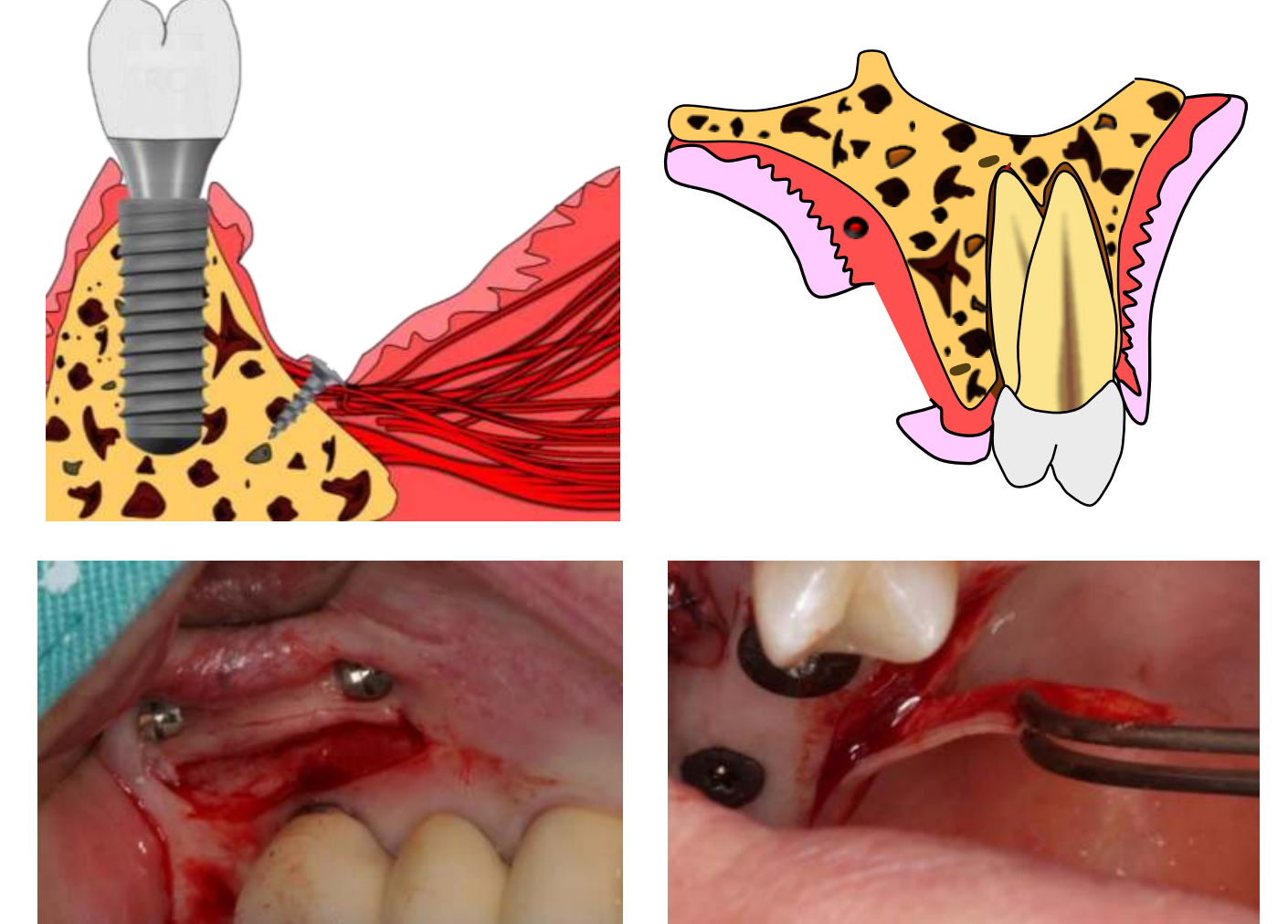

$\begin{array}{ll}\text { FGG } & \text { GRAFT IMMOVILIZATION. } \\ \text { FEL } & \text { SELF TAPPING SCREWS. }\end{array}$

$\begin{array}{ll}\text { FGIVA GRAFT } & \text { GRAFT IMMOVILIZATION. } \\ \text { FGG } & \text { SELF TAPPING SCREWS. }\end{array}$

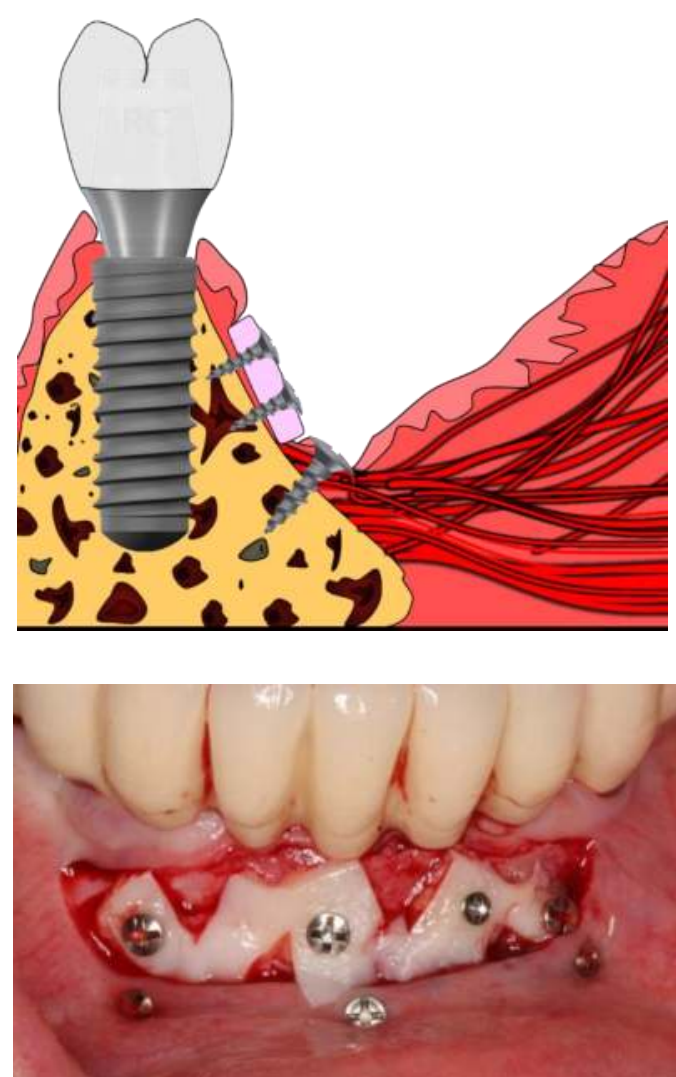

\section{Results}

At 10 days all free palatal grafts healed uneventful. At six month 30 implant sites showed clinical resolution of peri-implantitis. No further bone loss could be observed. At one year 29 implants showed resolution of perimiplant conditions. No further bone loss occured. At one year $91 \%$ of the implants showed a mean $2 \mathrm{~mm}$. creeping attachment over the exposed implant neck.
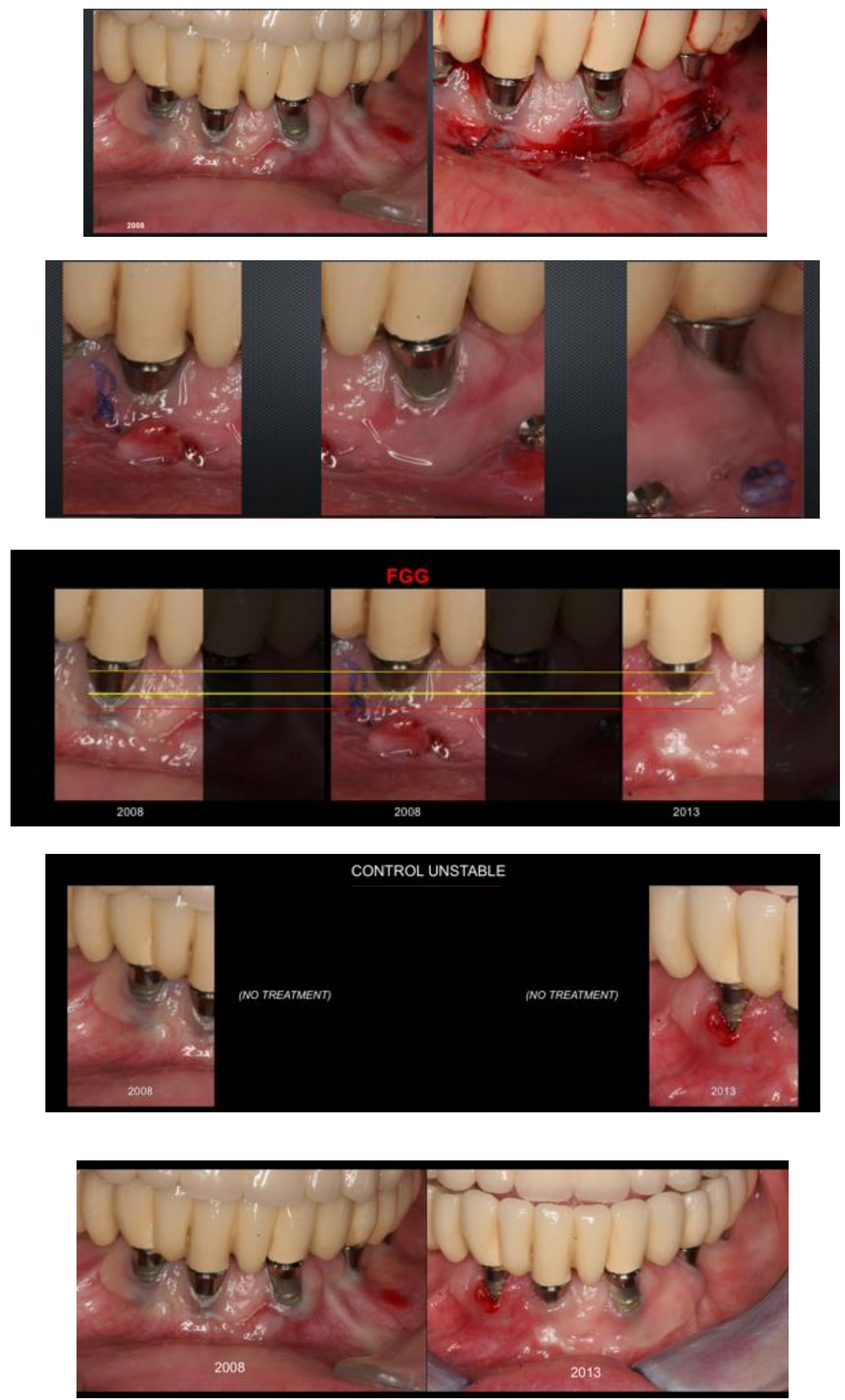

\section{Conclusions}

The procedure described in this series of cases lead to resolution of clinical signs of peri-implantitis in more than $90 \%$ of the cases. The use of self tapping microscrews for free epithelial graft fixation improve graft survival and favors a fast graft reepithelization. which lead to less graft shrinkage. Improvement of soft tissue condition around round implants favors a fenomena not previously described around implants called "Creeping attachment". Randomized, prospective studies are needed to further validate this technique.

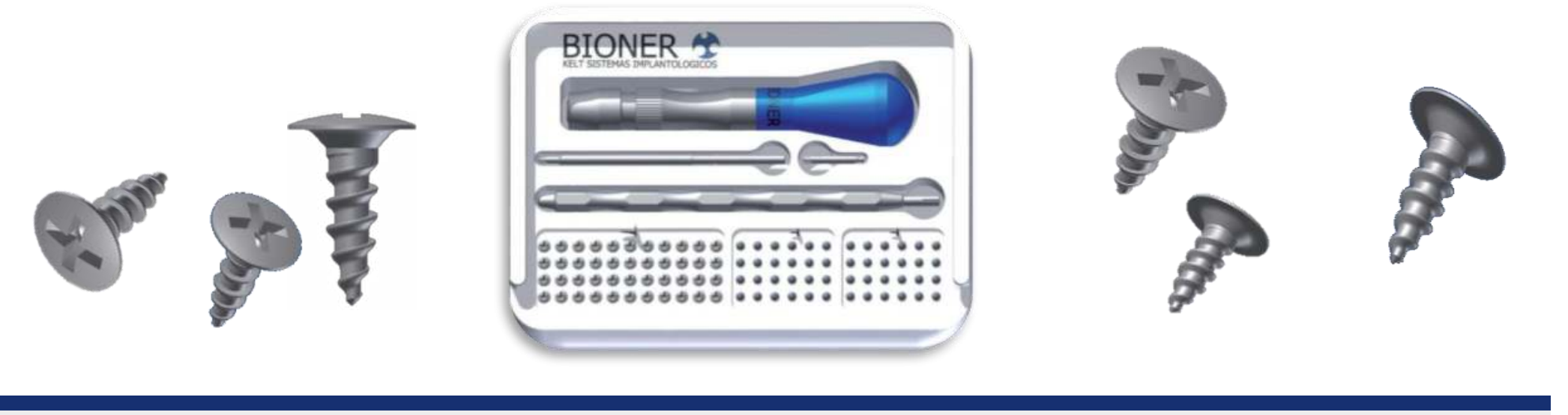

\section{References}

Lang, N. P., Berglundh, T Periimplant diseases: where are we now? - Consensus of the 7th European Workshop on Periodontology. Journal of Clinical Periodontology,

Sanz, M., Chapple, I. Clinical research on peri-implant diseases: consensus report of Working Group 4. Journal of Clinical Periodontology, 2012; 39: 202-206.

Morales Schwarz D. Fixation of soft tissue grafts with miniscrews and minipins. Clinical Oral Implants Research 2006, 17; 1xxxi. 